\title{
PESSOA NA TERCEIRA MARGEM DO ROSA
}

Pontifícia Universidade Católica de Minas Gerais - PUC Minas. Doutor. Mestre em Filosofia pela UFMG. Doutorando na Universidad Complutense de Madrid.
Sérgio Murilo Rodrigues

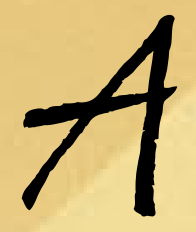

Resumo

interpretação canônica do conto "A terceira margem do rio", de Guimarães Rosa, nos fala da existência humana diante da morte. O pai morre (a canoa é o caixão) e vai para a dimensão transcendente - a terceira margem do rio. O filho permanece fiel à memória do pai, recusandose a esquecê-lo e, portanto, recusando-se a aceitar a morte do pai e a sua própria morte. Gostaria de propor uma interpretação diferente fazendo uma análise intertextual com o poema de Fernando Pessoa, "Navegar é preciso; viver não é preciso". Fernando Pessoa recebeu influência do existencialismo de Heidegger e de Sartre. Nesta interpretação, o conto de Guimarães Rosa é uma metáfora da condição humana. A terceira margem é simultaneamente o não-lugar da loucura e dos projetos de vida. O não-lugar não se confunde com nenhum lugar, pois ele indica um lugar que ainda não existe concretamente, mas que existe enquanto significador das ações existenciais. Eu estou direcionado para este lugar. Assim, o pai insiste em fixar o seu projeto individual (a canoa) em um rio que não para de correr (a finitude da vida; o transcorrer da temporalidade). Esta é a característica marcante da existência humana: a tentativa de enraizamento no fluxo contínuo do tempo vivido. Permanecer na mudança; fixar o transitório; banharse duas vezes no mesmo rio (segundo Heráclito, isso seria impossível, pois o rio já não é o mesmo, assim como você mesmo). Segundo Pessoa, viver não é necessário; o que é necessário é criar. Diante de uma existência humana sem nenhum sentido a priori, só nos resta criarmos, nós mesmos, um sentido para ela, através de um projeto de vida, mesmo que esse projeto seja ficar navegando no mesmo lugar de um rio.

Palavras-chave: Existência. Filosofia. Morte. Guimarães Rosa. Fernando Pessoa. 
O conto "A terceira margem do rio" faz parte do livro Primeiras estórias, de Guimarães Rosa, publicado em 1962. Todos os contos do livro versam sobre 'a vida do sertão', mas sempre com sentido de falar da existência humana em geral. O conto é narrado na primeira pessoa (o filho) e fala de um pai que resolveu, de repente, abandonar tudo para viver em uma pequena canoa no meio do rio. O tempo da narrativa é a existência do filho, que conta a sua persistência em velar o pai em um lugar que 'não existia', já que ele não aportava nem na margem esquerda e nem na direita do rio. O pai nunca mais pisou em terra firme e toda a família o abandona, só o filho permanece fiel a ele até chegar a velhice de ambos, quando, finalmente, o pai resolve trocar de lugar com o filho, que assustado, foge.

\footnotetext{
Sofri o grave frio dos medos, adoeci. Sei que ninguém soube mais dele. Sou homem, depois desse falimento? Sou o que não foi, o que vai ficar calado. Sei que agora é tarde, e temo abreviar com a vida, nos rasos do mundo. Mas, então, ao menos, que, no artigo da morte, peguem em mim, e me depositem também numa canoinha de nada, nessa água que não para, de longas beiras: e, eu, rio abaixo, rio a fora, ria a dentro - o rio (ROSA, 1976, p. 32).
}

As interpretações canônicas do conto apontam para a morte e a loucura como temas centrais. A história relataria o falecimento do pai, sendo a canoa o seu caixão. "Encomendou a canoa especial, de pau de vinhático, pequena, mal com a tabuinha da popa, como para caber justo o remador" (ROSA, 1976, p. 27). "A terceira margem do rio" seria a dimensão transcendente da memória, das lembranças ou mesmo, em um sentido religioso, de outra vida. O esforço do filho, então, consistiria em tentar manter viva a lembrança do pai, apesar de as urgências do cotidiano forçarem-no ao esquecimento. "Sustentar a lembrança do pai" pode ser entendido como a necessidade de as pessoas manterem viva a presença dos seus entes queridos que já se foram, mas também pode ser entendido como a dificuldade de se aceitar a morte como um fato da vida. O filho recusa-se a aceitar a morte do pai e o mantém vivo em um não-lugar indeterminado (a terceira margem). Segundo essa interpretação, o filho insiste em se parecer com o pai por via dos ensinamentos desse mesmo pai ausente, que havia abandonado a família.

Às vezes, algum conhecido nosso achava que eu ia ficando mais parecido com nosso pai. Mas eu sabia que 
ele agora virara cabeludo, barbudo, de unhas grandes, mal e magro, ficado preto de sol e dos pelos, com aspecto de bicho, conforme quase nu, mesmo dispondo das peças de roupas que a gente de tempos em tempos fornecia. Nem queria saber de nós; não tinha afeto? Mas, por afeto mesmo, de respeito, sempre que às vezes me louvavam, por causa de algum meu bom procedimento, eu falava: - "Foi meu pai que um dia me ensinou a fazer assim..."; o que não era o certo, exato; mas, que era mentira por verdade (ROSA, 1976, p. 30).

No final do conto, o pai aparece como um fantasma chamando o filho para ficar em seu lugar no caixão. Diante da morte, o filho treme de medo. Que culpa ele poderia ter de temer a morte? Ninguém tem culpa de sofrer o medo do nada, da ausência, da morte. "De que era que eu tinha tanta, tanta culpa? Se o meu pai, sempre fazendo ausência: e o rio-rio-rio, o rio - pondo perpétuo" (ROSA, 1976, p. 31).

Já o tema da loucura é recorrente em Rosa. Podemos percebêla com facilidade em dois outros contos de Primeiras estórias: "Sorôco, sua mãe, sua filha" e "A menina de lá". Nos três contos vemos referência a um não-lugar, ou seja, um lugar que só existe na cabeça das pessoas, embora possa vir a existir algum dia. $\mathrm{O}$ não-lugar é o lugar da falta de razão e, portanto, da loucura. Podemos entender as "margens do rio" como lugares da certeza, do padronizado, do racional. E a "terceira margem do rio" seria o lugar do incerto, do fora do padrão, da loucura.

Poucas são as características atribuídas ao pai no conto "A terceira margem do rio", mas, logo no início, ele é caracterizado como uma pessoa calada, ensimesmada, ilhada em seu próprio mundo do qual ninguém consegue retirá-lo. Ora, trata-se de características de pessoas consideradas loucas:

Nosso pai era homem cumpridor, ordeiro, positivo; e sido assim desde mocinho e menino, pelo que testemunharam as diversas sensatas pessoas, quando indaguei a informação. Do que eu mesmo me alembro, ele não figurava mais estúrdio nem mais triste do que os outros, conhecidos nossos. Só quieto (ROSA, 1976, p.27).

Se, nesse primeiro momento, Rosa insere o termo "sensatas pessoas" para fazer o contraponto à futura decisão do pai, com o desenvolvimento do conto, a referência à loucura vai se tornando mais clara. Diante da atitude do pai, "nossa mãe, vergonhosa, se portou com muita cordura; por isso, todos pensaram de nosso 
pai a razão em que não queriam falar: doideira" (ROSA, 1988, p. 32). No final do conto, o filho começa a pensar se não estaria ficando louco como seu pai. "Sem fazer véspera. Sou doido? Não. Na nossa casa, a palavra doido não se falava, nunca mais se falou, os anos todos, não se condenava ninguém de doido. Ninguém é doido. Ou, então, todos" (ROSA, 1976, p. 28).

A loucura seria um atributo de todos os homens, que buscam estar em um lugar que só existe na imaginação, mas não deixa de ser importante só por causa disso. Ora, rigorosamente falando "a terceira margem do rio não existe". Um rio só possui duas margens. Curioso notar também que o termo "terceira margem' só aparece no título do conto, ou seja, a narrativa não fala diretamente sobre o termo, deixando-o também em um não-lugar no próprio texto.

Depois de ter falado sobre as interpretações canônicas, gostaria de propor uma abordagem diferente, fazendo uma análise intertextual com um poema de Fernando Pessoa. Proponho que o tema central do conto seja a condição humana e que a terceira margem do rio signifique o não-lugar dos projetos de vida essenciais à existência humana. Essa interpretação é claramente inspirada no Existencialismo filosófico de Martin Heidegger (1889-1976) e de Jean-Paul Sartre (1905-1980). Especialmente Sartre que assumiu com todas as letras o caráter humanista do seu existencialismo (Heidegger, por sua vez, nega que o seu existencialismo seja humanista). Sem querer entrar em uma discussão complexa, profunda e extensa sobre as diferenças do existencialismo heideggeiriano para o sartreano, pode-se dizer que o ser humano em sua existência individual é um ser voltado para o futuro. Tal como o arqueiro que, para atirar a sua flecha, precisa fixar sua visão no alvo à frente $\mathrm{e}$ não na própria flecha, o indivíduo projeta constantemente a sua existência para um futuro que ainda não existe concretamente, mas apenas na imaginação. Trata-se do projeto de vida, essencial para a existência humana ter algum sentido, já que não nascemos com um sentido existencial pronto ou a priori e precisamos construí-lo com a própria existência. Por isso, a existência precede a essência e não a essência precede a existência, como ocorre com objetos e outros animais. O sentido da existência ou a essência da mesa ou do cavalo de corrida já está definido no surgimento do objeto e do animal: ser aquilo para o que foi projetado. No entanto, nós, seres humanos, somos seres jogados no mundo, ou seja, não temos um projeto pré-definido e, por isso, necessitamos passar pela angústia da decisão acerca de qual será o nosso projeto de vida: o que faremos 
com a nossa existência? E a resposta é uma projeção para um futuro que ainda não existe, mas se espera que exista. Toda a nossa existência fica tensionada, mobilizamos todos os nossos recursos, em direção a este não-lugar (o projeto de futuro).

Podemos inferir pelas características intelectuais de Pessoa, pelo seu interesse pela filosofia, que ele conhecia a corrente filosófica do existencialismo, embora não a cite explicitamente.

Em seu Textos Filosóficos encontramos menções a praticamente toda a gama de filósofos. Desde os gregos até os modernos (Heráclito, Parmênides, Zenão, Górgias, Platão, Protágoras, Sócrates, Anaxágoras, Aristóteles, Descartes, Kant, Leibniz, Berkeley, Vico, Nietzsche, Pascal, Schopenhauer ...), Fernando Pessoa sondou praticamente todas as possibilidades de posicionamentos do "eu" em face do mundo a ser conhecido. Daí que sua poesia adquira um valor limítrofe ao da filosofia: o que se abre para o Saber. Como ele próprio o diz a certa altura de suas reflexões: Uma corrente literária não passa de uma metafísica. Uma metafísica é um modo de sentir as coisas (...). As metafísicas têm gradações; são modos mais ou menos intensos, mais ou menos lúcidos de sentir o Universo (T.F. II-80) (COELHO, 1986, p. XXII - grifo meu).

O poema que gostaríamos de relacionar com "A terceira margem do rio", de Rosa, é "Mensagem à memória do Presidente-Rei Sidônio Pais (quinto Império)". Trata-se de um fragmento solto, manuscrito, sem data, encontrado em meio aos milhares de inéditos que Fernando Pessoa guardou em sua arca e publicado, pela primeira vez, em 1960:

Navegadores antigos tinham uma frase gloriosa: "Navegar é preciso; viver não é preciso".

Quero para mim o espírito (d)esta frase, transformada a forma para a casar com o que eu sou: Viver não é necessário; o que é necessário é criar.

Não conto gozar a minha vida; nem em gozá-la penso. Só quero torná-la grande, ainda que para isso tenha de ser o meu corpo e a (minha alma) a lenha desse fogo.

Só quero torná-la de toda a humanidade; ainda que para isso tenha de a perder como minha.

Cada vez mais assim penso. Cada vez mais ponho na essência anímica do meu sangue o propósito impessoal de engrandecer a pátria e contribuir para a evolução 
da humanidade. É a forma que em mim tomou o misticismo da nossa Raça (PESSOA, 1986, p. 1).

A frase "Navegar é preciso, viver não é preciso" é de autoria de Pompeu, um general romano que viveu entre 106-48 a.C., sendo pronunciada aos seus soldados que, em meio a uma tempestade, estavam temerosos por suas vidas. Essa frase ficou famosa pelo trabalho não de Pompeu, e sim de um estudioso e biógrafo de nome Plutarco (RIBEIRO, 2004), mesmo sendo escrita em grego, sua forma eternizada é latina e tinha o seguinte formato: Navigare necesse; vivere non est necesse.

A maior parte das interpretações dessa frase trabalha com a ambiguidade da palavra "preciso", que pode significar tanto precisão, exatidão, quanto necessidade. No caso de Pessoa, não temos tal dúvida, pois ele explicita o sentido com o qual ele irá trabalhar: "Viver não é necessário; o que é necessário é criar". Ou seja, uma vida sem objetivo, sem um projeto, não é necessária, ou melhor, não vale a pena ser vivida (SÓCRATES, 469 a.C. - 399 a.C.): uma vida não examinada não vale a pena ser vivida. Certamente que podemos entender "criar" aqui como uma referência à criação artística, mas também podemos interpretar como uma referência à criação de um sentido para a existência de um projeto de vida, de algo que faça a vida valer a pena ser vivida. E nesse sentido, esse projeto possui mais importância que a própria vida em sua individualidade egoísta: "só quero torná-la grande, ainda que para isso tenha de ser o meu corpo e a (minha alma) a lenha desse fogo." O corpo e a alma não são meramente para a sobrevivência, mas para viver uma vida com sentido. E não se trata de uma decisão pessoal dele, Fernando Pessoa, mas de uma condição da existência humana como tal. "Só quero torná-la de toda a humanidade; ainda que para isso tenha de a perder como minha." Talvez, para seguir o projeto escolhido, o sujeito seja obrigado a abandonar tudo, até a própria personalidade, mas não haverá problema algum, pois o importante é manter o "misticismo da nossa Raça" (os seres humanos em sua condição de ser-de-projeto).

Voltemos agora ao conto de Rosa. A "terceira margem do rio" é o não-lugar dos projetos existenciais inerentes à condição humana. Somos seres de possibilidades e o possível é algo que pode ser, mas ainda não é. O pai direciona a sua canoa (sua existência individual), não para as concretas e certas margens direita e esquerda do rio, mas para a imaginária terceira margem, lugar do seu projeto de vida. Vamos dar um exemplo bem simples, um estudante de medicina faz o mesmo: ele 
abandona as suas certezas para se lançar em um longo projeto de sete anos, que só existirá concretamente no dia em que ele obtiver o seu diploma de formado. Durante sete anos ele ficará "em uma canoa", como no dizer de Rosa:

\footnotetext{
e a canoa saiu se indo - a sombra dela por igual, feito jacaré, comprida longa. Nosso pai não voltou. Ele não tinha ido a nenhuma parte. Só executava a invenção de se permanecer naqueles espaços do rio, de meio a meio, sempre dentro da canoa, para dela não saltar, nunca mais (ROSA, 1976, p. 28).
}

Em certo sentido, o projeto de se formar em medicina é loucura. Doideira passar tanto tempo, dedicar tanto esforço, tantos sacrifícios para realizar um sonho, um projeto imaginário, que só existirá (se existir um dia, pois não há garantias) daqui sete anos. Talvez o exemplo da medicina não seja o melhor, pois é um curso que tem um alto grau de certeza de ser uma profissão bem-sucedida, talvez fosse melhor falar de outros cursos ou outros projetos. Mas faço isso de propósito para lembrar que Guimarães Rosa formou-se em medicina, mas nunca exerceu a profissão. "Ninguém é doido. Ou, então todos." Importante observar que não se trata de uma avaliação qualitativa ou quantitativa do projeto de vida de cada um, mas de mostrar que todo projeto vale a pena ser vivido quando ele é autêntico, quando o sujeito adere a ele de corpo e alma.

Assim temos "o rio, por aí se estendendo grande, fundo, calado que sempre" representando o tempo que reúne todas as existências em uma história da humanidade, um grande rio, que a todos carrega para o mar infinito. O tempo implacável não espera ninguém, num eterno fluir que não pode ser parado (o ir $\leftarrow \rightarrow$ o ri o). Apesar disso, nós, seres humanos, queremos ficar parados nesse rio (a canoa parada na terceira margem), queremos nos enraizar nas correntezas do rio. Novamente temos a busca do sentido, do projeto de vida, como uma tentativa impossível de fixação no fluxo ininterrupto do tempo. Esta é a característica marcante da existência humana: a tentativa de enraizamento no fluxo contínuo do tempo vivido. Permanecer na mudança; fixar o transitório; banhar-se duas vezes no mesmo rio (segundo Heráclito isso seria impossível, pois o rio já não é o mesmo, assim como nós não seríamos).

E o filho que não abandona o pai? Ele tenta se apropriar do projeto de vida do pai, mas na canoa/projeto só cabe um. Projetos de vida são constitutivos da condição humana, mas a 
escolha do projeto é individual. O pai escolheu ficar no meio do rio, parado, em uma canoa. É loucura? Não para ele. Projetos de vida não podem ser compartilhados. Compartilhar um projeto é, na realidade, assumir o seu projeto como um projeto que serve para outros, mas a sua maneira de executar o projeto será só sua. O filho não pode viver a vida do pai. Ele só pode viver a própria vida. Ele demora a descobrir isso. Quando o pai aceita entregar-lhe a canoa, ele foge assustado, com medo de não ter vivido a própria vida depois daquele tempo todo (uma vida não examinada).

Rosa, como Pessoa, vê a existência humana direcionada para um projeto de vida como uma condição geral da nossa existência. Por isso, ele não utiliza nomes próprios, mas nomes genéricos que representam a humanidade em geral, incluindo todos nós: nosso pai, filho, mãe.

Curiosamente, afirmamos a nossa vida diante da negação da vida que a morte representa. Diante da inevitabilidade da morte, necessito de um sentido que valorize a minha vida diante do nada. Fernando Pessoa viveu muitas vidas através de seus heterônimos e Rosa utiliza várias frases negativas com o sentido de afirmativas em seu conto: "nosso pai nada não dizia; ele não tinha ido a nenhuma parte; só se encobrindo de não saber; era mentira por verdade; no não-encontrável. Sou o que não foi." (ROSA, 1976, p. 27)

Essa interpretação é fundamentada nas aulas da professora de filosofia da FAFICH/UFMG, Sônia Viegas. Não encontrei ainda nenhuma publicação com essas aulas e, portanto, não posso citá-la segundo as regras, mas não posso deixar de fazer uma homenagem à professora que apontou para tantos a direção de uma "terceira margem do rio" para a qual cada um poderá fazer a sua canoinha justa para caber apenas um.

\section{PESSOA ON ROSA'S THIRD BANK}

ABSTRACT

The canonical interpretation of the short story "The third bank of the river," by Guimarães Rosa, deals with the human existence in the face of death. The father dies (the canoe is the gloomy coffin) and goes to a transcendent dimension - the third bank of the river. 
Ceserns

\section{Sérgio murilo Rodrigues}

The son remains true to his father's memory, refusing to forget him and therefore refusing to accept his father's and his own death. I would like to propose a different interpretation, that is, to make an intertextual analysis with Fernando Pessoa's poem, "Sailing is necessary; living is not necessary". Fernando Pessoa was influenced by Heidegger and Sartre's existentialism. In this interpretation, Rosa's short story is a metaphor of the human condition. The third riverbank is simultaneously the non-place of madness and the non-place of life's projects. The non-place cannot be confused with nowhere because it indicates a place that does not yet exist concretely, but exists as a signifier of existential actions. We are all oriented towards this place. Thus, the father insists by fixing his individual project (canoe) in a river that never stops running (the finiteness of life, the passing of temporality). This is the hallmark of human existence: the attempt to root in the continuous flow of lived time. To remain in the change; to fixate the transitory; to bathe oneself twice in the same river (according to Heraclitus, this would be impossible because the river is no longer the same, as well as yourself). According to Pessoa, living is not necessary; what is needed is to create. Faced with a human existence without any meaning, we can only create ourselves a meaning for it through a life project, even if the project is to sail forever in the same place in a river.

Keywords: Existence. Philosophy. Death. Guimarães Rosa. Fernando Pessoa

\section{REFERÊNCIAS}

COELHO, Nelly Novaes. Introdução. In: PESSOA, Fernando. Obra poética - Volume único. Rio de Janeiro: Nova Aguilar, 1986.

PESSOA, Fernando. Obra poética Rio de Janeiro: Nova Aguilar, 1986.

RIBEIRO, Wilson. A coletânea sobre história grega. 2004. Disponível em: <http://www.warj.med.br/his/hisO2f.arp>

ROSA, João Guimarães. Primeiras estórias. Rio de Janeiro: José Olympio Editora, 1976.

Recebido em: 24/06/2015

Aceito em: 09/12/2015 